\title{
Dimensão crítica e design de material didático no contexto dos Centros de Estudos de Línguas do Estado de São Paulo: o caso do inglês
}

\author{
Rômulo Francisco de Souza \\ Universidade de São Paulo \\ romulosouza@usp.br
}

\section{Resumo}

Investigamos o material didático do curso de inglês dos Centros de Estudos de Línguas do Estado de São Paulo (CEL) buscando perceber indícios que apontem para a presença de uma dimensão crítica em seu design. Nossa análise, embasada em aspectos da Pedagogia Crítica e da Pedagogia PósMétodo, orientou-se a partir de três eixos fundamentais: a temática central das unidades; a utilização dos códigos; e a maneira como esses códigos são explorados. Percebemos que o material didático parece não se alinhar com uma perspectiva crítica, assumindo um currículo oculto de não questionamento do status quo e concebendo língua e seu contexto de ensino e aprendizagem como algo desconectado de questões político-sociais. O material didático parece-nos, dessa forma, não contribuir para o estabelecimento de uma proposta pedagógica comprometida com a formação cidadã de seus alunos aprendizes dos CEL. Compreendemos que os resultados de nossa análise poderão servir como referência para a produção de material didático em que se considere a dimensão crítica em seu design, seja para o inglês, seja para os outros idiomas ofertados pelo Centro de Estudos de Línguas.

Palavras-chave: Pedagogia Crítica. Pedagogia Pós-Método. Centro de Estudos de Línguas do Estado de São Paulo. Material didático. Inglês.

\begin{abstract}
In this paper, we investigate the English language teaching material of the Language Studies Centers of the State of São Paulo (CEL), seeking to perceive indications that point to the presence of a critical dimension in its design. Our analysis, based on aspects of Critical Pedagogy and Post-Method Pedagogy, was guided by three fundamental axes: the central theme of the units; the use of codes; and the way these codes are explored. We note that the material does not seem to align with a critical perspective, assuming a hidden curriculum of
\end{abstract}


non-questioning of the status quo and conceiving language and its context of teaching and learning as something disconnected from socio-political issues. This way, we understand that the material does not seem to contribute to the establishment of a pedagogical proposal committed to the citizenship education of its students. We understand that the results of our analysis can contribute as a reference to the production of language teaching material that considers the critical dimension in its design, either for English or for the other languages offered by the Language Studies Centers.

Keywords: Critical Pedagogy. Post-Method Pedagogy. English Language Teaching Materials. English.

\section{Apresentação}

Trazemos para debate, neste artigo, os resultados da análise que fizemos da coleção de livros didáticos utilizados no âmbito do curso de inglês dos Centros de Estudos de Línguas (doravante CEL) do Estado de São Paulo. Procuramos, em nossa análise, observar se o material didático apresenta indícios de uma dimensão crítica e, em caso afirmativo, de que maneira o faz. Trata-se dos resultados parciais de nossa pesquisa de pós-doutorado, em andamento, na Faculdade de Filosofia, Letras e Ciências Humanas da Universidade de São Paulo, com o apoio do Programa Nacional de Pós-Doutorado da Capes (PNPD-Capes), em que investigamos a problemática do material didático no contexto dos CEL.

Embasamos nossa análise em três aspectos fundamentais, os quais, consideramos, poderiam deflagrar a presença ou a ausência de uma dimensão crítica (CROOKES, 2013; GUILHERME, 2002; MACLAREN, 1995; PENNYCOOK, 1999, 2001; RAJAGOPALAN, 2003; SIQUEIRA, 2013) na composição do material didático. São eles: 1) a temática central das unidades; 2) a utilização dos códigos (CROOKES, 2013; WALLERSTEIN, 1983); e 3) a maneira como esses códigos são explorados.

Interessa-nos essa temática uma vez que nossa pesquisa de pósdoutorado se orienta pela hipótese de que materiais didáticos elaborados com base na perspectiva da Pedagogia Pós-Método (KUMARAVADIVELU, 2003) - uma perspectiva de viés essencialmente crítico - figuram como os mais adequados para o contexto dos CEL. 
Corrobora nossa hipótese a referência à formação cidadã do aprendiz, anunciada na apostila de inglês dos CEL, como uma das dimensões a serem contempladas pelo curso por meio de sua utilização. De fato, conforme lemos na apresentação da apostila, "os cursos oferecidos pelo CEL pretendem dar condições necessárias para sua formação, tanto quanto aluno como cidadão" (CAMPOS et al., 2014).

Dessa forma, o recorte que apresentamos aponta, especialmente, para o parâmetro da possibilidade (KUMARAVADIVELU, 2003), o qual, em linhas de síntese, diz respeito à noção de que o ato de ensinar e aprender línguas, mesmo em contexto formal, não se limita aos elementos linguísticos e funcionais da língua alvo, mas abrange, também, a dimensão sociopolítica que os aprendizes, como indivíduos pertencentes a uma sociedade, carregam consigo para a sala de aula.

\section{A pedagogia pós-método e o parâmetro da possibilidade}

A Pedagogia Pós-Método pode ser compreendida como o resultado de uma mudança de paradigma no campo de ensino e aprendizagem de línguas. Seus princípios essenciais, remontando-se ao início da década de 1990, fundamentam-se na chamada condição pósmétodo, a qual, conforme Kumaravadivelu (2003), define-se em torno de três atributos correlacionados: a busca por uma alternativa ao método (e não um método alternativo); a autonomia do professor; e a noção de pragmatismo baseado em princípios, a qual, em linhas gerais, reflete a ideia de uma pedagogia pragmática (WIDDOWSON, 1990) em que "a aprendizagem em sala de aula pode ser formatada e reformatada pelo professor como resultado de sua observação, análise e avaliação" (KUMARAVADIVELU, 2003, p. 33) por meio de uma postura engajada, reflexiva e crítica.

Trata-se de uma perspectiva, portanto, que rompe com uma tradição de ensino e aprendizagem embasada na concepção de métodos (KUMARAVADIVELU, 1994), sendo esses compreendidos como construtos teóricos de caráter prescritivo (PENYCOOK, 1989) que informam como um idioma deve ser ensinado, restando ao docente a tarefa de executá-lo em sala de aula. 
Em linhas de síntese, conforme discutimos e parafraseamos em Souza (2014), a Pedagogia Pós-Método será percebida por Kumaravadivelu (2001; 2006) como um sistema tridimensional composto por três parâmetros pedagógicos também inter-relacionados: o parâmetro da particularidade, o da praticabilidade e o da possibilidade (Figura 1).

Figura 1. Parâmetros da Pedagogia Pós-Método

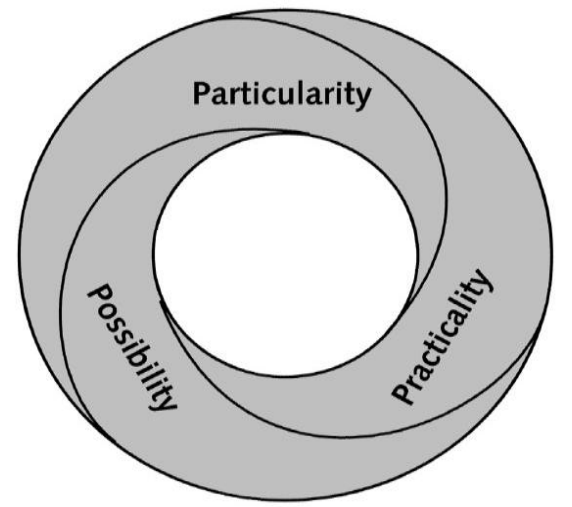

Fonte: adaptado de Kumaravadivelu (2003)

Esses parâmetros, como observa Kumaravadivelu (2003, p. 37), não possuem limites rigorosos entre si. Suas características sobrepõemse em determinados aspectos, estabelecendo uma dinâmica de correlação em que são moldados e remoldados uns pelos outros. Os resultados dessa relação, como lembra o autor, vão variar de acordo com o contexto, dependendo do que os participantes apresentam.

O parâmetro da particularidade está relacionado a uma "compreensão verdadeira das particularidades linguísticas, socioculturais e políticas locais" (KUMARAVADIVELU, 2001, p. 544), ou seja, a uma opção pedagógica sensível ao contexto, que, portanto, rejeita a adoção de princípios genéricos e predeterminados com o objetivo de cumprir objetivos também genéricos e predeterminados.

O parâmetro da praticabilidade, por sua vez, está relacionado à rejeição de um modelo artificial marcado pela relação dicotômica entre aquele que elabora a teoria - ou seja, o teórico - e aquele que consome 
a teoria - ou seja, o docente. Com efeito, na perspectiva da Pedagogia Pós-Método, os professores são encorajados a "teorizar a partir de sua prática e praticar o que teorizaram" (KUMARAVADIVELU, 2001, p. 545).

O parâmetro da possibilidade, enfim, está relacionado à opção de trazer à tona, em sala de aula, a consciência sociopolítica que os aprendizes carregam consigo, rejeitando, dessa forma, a concepção de que o ensino e a aprendizagem de línguas se restringem aos elementos linguísticos e funcionais. Conforme nos lembra Kumaravadivelu (2001, 2006), esse parâmetro tem inspiração, principalmente, na obra do educador brasileiro Paulo Freire, refletindo, também, os trabalhos de alguns de seus seguidores, entre os quais os educadores Simon (1988), Giroux (1988), McLaren (1995) e os linguistas aplicados Auerbach (1995), Benesch (2001) e Pennycook (2001).

Esses pensadores pressupõem que relações de poder e dominação permeiam todo e qualquer contexto pedagógico, sendo, tais contextos, empregados para criar e sustentar desigualdades sociais (KUMARAVADIVELU, 2003). A superação dessas desigualdades requer o emprego de uma pedagogia transformadora, de um fazer pedagógico crítico que, principalmente por meio da tomada de consciência a respeito do seu lugar nos diversos âmbitos sociais em que se inserem, empodere professores e aprendizes de modo que possam, também, ter condições de romper com as forças socialmente construídas e historicamente determinadas a que estão sujeitos dentro e fora da sala de aula (KUMARAVADIVELU, 2003). Conscientizar-se do seu lugar e de suas condições em relação à sociedade significa, em outras palavras, reconhecer sua própria identidade, sua classe, sua raça, seu gênero, sua etnicidade (KUMARAVADIVELU, 2003).

Nesse sentido, Crookes (2013) parece concordar com Kumaravadivelu (2003), quando defende que o fazer pedagógico crítico significa

[..] ensinar para justiça social, de modo a favorecer o desenvolvimento de cidadãos ativos e engajados que irão, conforme as circunstâncias permitem, questionar de modo crítico o motivo pelo qual as vidas de muitos seres humanos, talvez incluindo as próprias vidas, são materialmente, 
Dimensão crítica e design de material didático...

psicologicamente, socialmente e espiritualmente inadequados $[\ldots]$ cidadãos que serão preparados para procurar soluções para os problemas que enfrentam, ou com os quais se deparam, e tomar ações de acordo com tais problemas (CROOKES, 2013, p. 8). ${ }^{1}$

Consonantes com Kumaravadivelu (2003) e Crookes (2013) estão também Penycook (1999), Canagarajah (2005), Akbari (2008), Rajagopalan (2003), Giroux (1995) e Santos (2002). Os autores e a autora abordam aspectos e implicações relacionados à noção de pedagogia crítica e a um fazer pedagógico crítico, os quais reunimos no Quadro 1.

$1[\ldots]$ teaching for social justice, in ways that support the development of active, engaged citizens who will, as circumstances permit, critically inquire into why the lives of so many human beings, perhaps including their own, are materially, psychologycally, socially, an spiritually inadequate (...) citizens who will be prepared to seek out solutions to the problems they define and encounter, and take action accordly (CROOKES, 2013, p. 8). 
Quadro 1. Aspectos e concepções relacionados à ideia de pedagogia crítica e a um fazer pedagógico crítico ${ }^{2}$

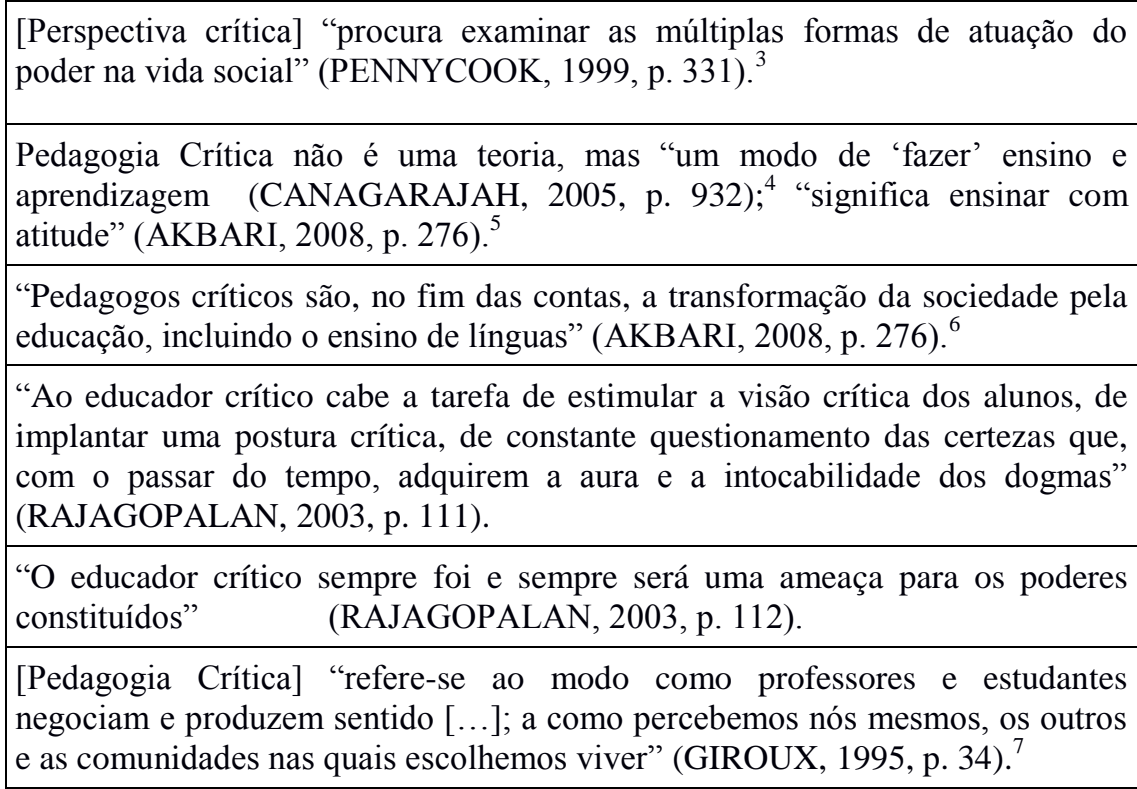

2Inspirado em Siqueira (2017)

$3[\ldots]$ seeks to explore multiple ways in which power may operate in social life (PENNYCOOK, 1999, p. 331).

$4[\ldots]$ a way of 'doing”' learning and teaching (CANAGARAJAH, 2005, p. 932).

5[...] it is teaching with an attitude(AKBARI, 2008, p. 276).

6 What critical pedagogues are after is the transformation of society through education, including language teaching (AKBARI, 2008, p. 276).

7“"...] refers to the process by which teachers and students negotiate and produce meaning. [...] how we represent ourselves, others, and the communities in which we choose to live (GIROUX, 1995, p. 34). 


\section{Quadro 1. Continuação}

[Pedagogia Crítica] "fornece um ponto de partida para correlacionar conhecimento e poder, bem como para um comprometimento com o desenvolvimento de modos de vida em comunidade que considerem seriamente a luta por democracia e justiça social” (GIROUX, 1995, p. 34). ${ }^{8}$

“A pedagogia crítica [...] [preocupa-se com] o 'como' e 'a que interesses' o conhecimento, as formações culturais são produzidos e distribuídos, atuando como instrumentos de legitimação de formas hegemônicas de poder" (SANTOS, 2002, p. 10).

[Pedagogia Crítica] "deseja fomentar a visão crítica dos cidadãos, capacitandoos a resistir, ainda que de forma limitada [aos] efeitos de poder" (SANTOS, 2002, p. 10).

"Focamos em uma pedagogia crítica [...] visando preparar cidadãos para participação em uma sociedade democrática" (RIASATI; MOLLAEI, 2012, p. 224). ${ }^{9}$

"Aprendizes são ativos na sala de aula e na sociedade, na pedagogia crítica" (RIASATI; MOLLAEI, 2012, p. 224). ${ }^{10}$

Coerente com os autores citados parece ser o ponto de vista de Shor (1992). O pesquisador associa a Pedagogia Crítica ao desenvolvimento de hábitos que permitem compreender o sentido profundo, "as raízes, as causas, o contexto social, a ideologia e as consequências pessoais de cada ação, avento, objeto, processo, organização, experiência, texto, questão subjetiva, política, media social e discurso" (SHOR, 1992, p. 129). Ele se refere aos hábitos de leitura, escrita e fala, os quais devem ir além do significado aparente, "das primeiras impressões, dos mitos dominantes, dos pronunciamentos

$8[\ldots]$ it provides a starting point for linking knowledge to power and a commitment to developing forms of community life that take seriously the struggle for democracy and social justice (GIROUX, 1995, p. 34).

9 We focus on a critical pedagogy [...] because of the goal of preparing citizens for participation in a democratic society (RIASATI; MOLLAEI, 2012, p. 224).

10Learners are active in the classroom and in society in critical pedagogy (RIASATI; MOLLAEI, 2012, p. 224). 
oficiais, dos clichês tradicionais, dos saberes recebidos e dos meros pareceres" (SHOR, 1992, p. 129).

\section{Códigos e diálogos: elementos essenciais de uma prática crítica}

Crookes (2013), com base no trabalho do pedagogo brasileiro Paulo Freire, classifica os códigos (ou codificadores) como um dos principais componentes de uma prática pedagógica de ensino de línguas de viés crítico. De forma geral, o autor compreende os códigos como dispositivos projetivos por meio dos quais os aprendizes podem articular sua própria interpretação a respeito de uma situação potencialmente problemática para sua vida (CROOKES, 2013). Tal interpretação, carregando uma certa imprevisibilidade, permite que o professor ofereça referências, potencialmente significativas para o aprendiz, sem a necessidade de determinar ou controlar o conteúdo.

Wallerstein (1983), como também discutido em Crookes (2013), traz uma definição de código estreitamente ligada à de Freire (1970). A autora define códigos como:

[..] expressões físicas concretas que reúnem todos os elementos de um tema em uma representação. Eles podem tomar diferentes formas: fotografias, desenhos, colagens, histórias, diálogos escritos, filmes, músicas. Códigos são mais do que subsídios para o ensino. Eles estão no coração do processo educacional, uma vez que iniciam o pensamento crítico. Independentemente da forma, um código é um dispositivo de projeção, emocionalmente significativo e identificável pelos estudantes. Discussões sobre o problema liberam energia que podem estimular a criatividade $\mathrm{e}$ aumentar a motivação para o uso do inglês [ou de outras línguas] (WALLERSTEIN, 1983, p. 19). ${ }^{11}$

11 Concrete physical expressions that combine all the elements of the theme into one representation. They can take many forms: photographs, drawings, collages, stories, written dialogues, movies, songs. Codes are more than visual aids for teaching. They are at heart of the educational process because they initiate critical thinking. No matter what the form, a code is a projective device that is emotionally laden and identifiable to 
Embasada em Freire (1970), ela lembra que os códigos resumem (ou codificam) as possíveis contradições que os aprendizes, como indivíduos, podem reconhecer em suas vidas. Os códigos, de fato, "codificam" essas contradições em enunciados. Wallerstein (1983) cita como exemplos de contradições a necessidade do inglês versus a perda da cultura nativa; stress no trabalho versus necessidade do trabalho; desapontamento versus esperança com base nas expectativas sobre os Estados Unidos (ou outro país para o qual se imigrou). A autora aponta, ainda, cinco características que, segundo ela, deveriam apresentar um bom código. Reunimos essa lista no Quadro 2.

Trazemos como exemplo de código a foto de uma campanha de prevenção e combate ao assédio sexual no sistema de metrô de Boston realizada pela Massachusetts Bay Transportation Authority (Figura 2). Trata-se de um problema urbano também enfrentado no sistema de metrôs de São Paulo e abordado em forma de campanha pela empresa Viaquattro, responsável pela administração de uma de suas linhas. Consideramos como público-alvo do código (Figura 2) os alunos e alunas dos CEL da cidade de São Paulo, para os quais essa questão consiste em uma situação potencialmente problemática do seu quotidiano. O código carrega elementos que podem trazer à tona o conflito entre a necessidade de uso do metrô e a questão da possibilidade de assédio, permitindo que se discutam, com os aprendizes, propostas de soluções ou de pequenas ações visando a contribuir com a resolução desse conflito ou problema.

students. Discussion of the problem will liberate energy that can stimulate creativity and raise motivation for using English (WALLERSTEIN, 1993, p. 19). 
Quadro 2. Características de um bom código ${ }^{12}$

1. Deve representar uma situação problemática quotidiana que seja imediatamente reconhecível pelos estudantes. (Eles já conhecem profundamente o que está sendo colocado em debate.)

2. A situação, escolhida porque gera efeitos pessoais e sociais, é apresentada como um problema com contradições inerentes. O código (imagem, estória, etc.) deve ilustrar o máximo possível de lados da contradição, ainda que seja simples o suficiente para que os estudantes projetem sua própria experiência.

3. O código deve focar em um problema por vez, mas não em um modo fragmentado. Ele deve sugerir conexões a outros temas na vida das pessoas.

4. O código não deve apresentar soluções para o problema, mas permitir que os estudantes desenvolvam suas próprias soluções com base em suas experiências.

5. O problema apresentado não deve ser demasiadamente pesado para os estudantes. Deve haver espaço para pequenas ações que abordem o problema, mesmo que eles não o resolvam. Questões da comunidade local geralmente fornecem oportunidades para que os estudantes tenham impacto com ações de pequena escala.

Fonte: adaptado de Wallerstein (1983, p. 20)

121) It must represent a daily problem situation that is immediately recognizable to students. (They already deeply know what is being talked about); 2) That situation, chosen because it contains personal and social affect, is presented as a problem with inherent contradictions. The code (pictures, story, etc.) should illustrate as many sides of the contradiction as possible, yet be simple enough for students to project their own experience; 3) The code should focus on one problem at a time, but not in a fragmented way. It should suggest connections to other themes in people's lives. 4) The code should not provide solutions to the problem, but should allow students to develop their own solutions from their experience; 5) The problem presented should not be overwhelming to students. There should be room for small actions that address the problem even if they don't solve it. Local community issues usually provide opportunities for students to have an impact with smallscale actions (WALLERSTEIN, 1983, p. 20). 
Figura 2. Exemplo de código - campanha de prevenção e combate ao assédio sexual no sistema de metrô de Boston

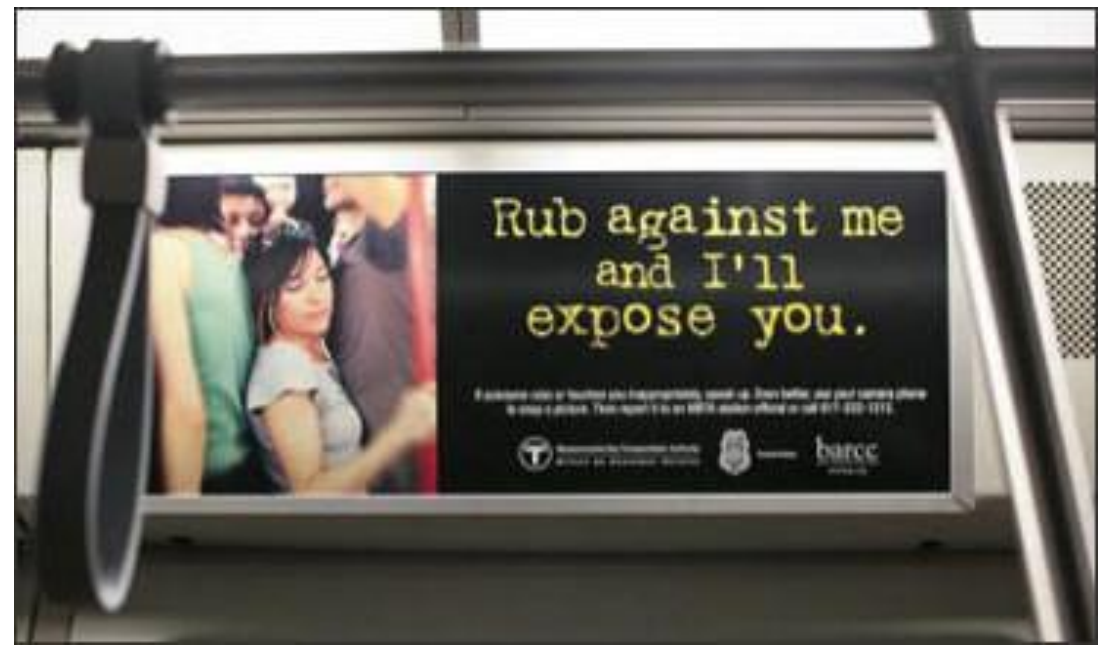

FONTE: adaptado de Massachusetts Bay Transportation Authority

Atrelada a essa noção de código como um dos elementos essencialmente constitutivos de uma prática crítica (FREIRE, 1970; WALLERSTEIN, 1983; CROOKES, 2013) está o diálogo constante entre alunos e professor. Diálogo entendido aqui não como um texto ou gênero textual que aparece, tradicionalmente, no início de uma unidade de um livro didático de língua estrangeira, mas sim como a conversa informal entre aprendizes, em pares, em grupos ou entre aprendizes e professor (CROOKES, 2013).

De fato, é nessa interação que o docente poderá perceber quais contradições os aprendizes trazem consigo para o contexto de ensino e aprendizagem para, posteriormente, codificá-los ou trazê-los em forma de códigos. É também nessa interação que o aprendiz poderá gerar pensamento crítico, inserindo-se em uma situação de educação verdadeira, entendida como prática da liberdade (FREIRE, 2011). De fato, para Freire:

Somente o diálogo, que implica num pensar crítico, é capaz, também, de gerá-lo. Sem ele, não há comunicação e sem esta não há verdadeira 
educação. A que, operando a superação da contradição educador-educandos, se instaura como situação gnosiológica, em que os sujeitos incidem seu ato cognoscente sobre o objeto cognoscível que os mediatiza. Daí que, para esta concepção como prática da liberdade, a sua dialogicidade comece, não quando o educador-educando se encontra com os educandos-educadores em uma situação pedagógica, mas antes, quando aquele se pergunta em torno do que vai dialogar com estes (FREIRE, 2011, p. 115).

Pressupõe-se, a partir daí, a figura do educador-educando, que, ao contrário do educador-bancário, antidialógico, se coloca como problematizador, compreendendo o conteúdo programático da educação não como algo a ser doado ou imposto, mas, sim, devolvido ao povo (nesse caso, aos aprendizes) de forma organizada, sistematizada e acrescentada, aquilo que eles lhe entregaram de forma desestruturada (FREIRE, 2011), por meio do diálogo.

\section{O material didático de inglês do CEL}

O material didático dos cursos de inglês dos Centros de Línguas - elaborado por uma equipe de especialistas da Secretaria de Educação do Estado de São Paulo em conjunto com professores e professoras advindos do contexto público com experiência tanto nesse âmbito quanto em institutos particulares de idiomas (CELTEACHERS, 2009) - começou a ser utilizado nos CEL a partir do ano de 2014. Esse material consiste em uma coleção de apostilas com três volumes, reunindo um total de oito unidades, cujos temas destacamos por meio do Quadro 3. 
Quadro 3. Unidades e temas das apostilas de inglês do CEL de SP

\begin{tabular}{|l|l|}
\hline Vol. 1 & $\begin{array}{l}\text { Unit 1 - At the hotel } \\
\text { Unit 2 - At the hotel II } \\
\text { Unit 3 - Travelling to Brazil }\end{array}$ \\
\hline Vol. 2 & $\begin{array}{l}\text { Unit 4 - Leisure time } \\
\text { Unit 5 - Different countries, different habits, different cultures } \\
\text { Unit 6 - Helt and nutrition issues }\end{array}$ \\
\hline Vol. 3 & $\begin{array}{l}\text { Unit 7 - At the mall } \\
\text { Unit 8 - Cultural aspects, celebration and festivals }\end{array}$ \\
\hline
\end{tabular}

Seu objetivo, conforme anunciado em sua apresentação, consiste em oferecer a oportunidade do estudo do inglês com vistas à atuação no mercado de trabalho e à inclusão social, considerando, também, como acenado neste artigo, a formação cidadã do aprendiz. Trata-se de uma proposta de viés comunicativo, uma vez que prevê, conforme os autores, o desenvolvimento da competência comunicativa, considerando os diversos contextos de uso do inglês como língua internacional em situações do quotidiano. É uma proposta que privilegia a comunicação oral, funcionando, ainda segundo consta em sua apresentação (CAMPOS et al., 2014), como complemento ao ensino regular do inglês na rede pública do Estado de São Paulo, o qual, por sua vez, visa ao desenvolvimento das competências leitora e escritora (CAMPOS et al., 2014).

\section{Análise do material didático: em busca da dimensão crítica}

A análise que fizemos envolveu os três volumes do material didático de inglês dos Centros de Estudos de Línguas da rede estadual de São Paulo. Como anunciamos na introdução deste artigo, essa análise buscou perceber a presença de uma dimensão crítica no design do material didático, sendo nossos olhares direcionados por três eixos fundamentais: 1) a temática das unidades; 2) a utilização dos códigos; e 3) a maneira como esses códigos são explorados.

De forma geral, percebemos que o material didático parece não se alinhar com uma postura crítica, optando por uma concepção de língua como mero exercício intelectual, desconectado de questões político-sociais, assumindo um currículo oculto (GIROUX et al., 1981; 
MCLAREN, 1989; SLATTERY, 2006) que sugere uma falsa neutralidade, quando, de fato, esconde ideologias que o comprometem com o não questionamento do status quo, o qual, muitas vezes, submete alunos e professores à condição de oprimidos.

De fato, ainda que seja amplamente ilustrado, que traga determinados aspectos da cidade de São Paulo e do Brasil e que na unidade 6 apresente textos com dicas de saúde e de alimentação saudável, o material didático não apresenta, do nosso ponto de vista, qualquer elemento que pudesse representar um código (CROOKES, 2013; WALLERSTEIN, 1983). Tampouco apresenta algum tipo de atividade que motive a reflexão e o pensamento crítico com base em seus elementos constitutivos (textos, imagens, etc.), sendo ou não caracterizados como códigos.

Vale ressaltar que nossa percepção encontra correspondência nas reflexões de Akbari (2008), corroborando-as. O autor, de fato, observa que:

As forças conservadoras que controlam a educação e a sociedade em geral tentaram manter as ideias críticas fora do currículo escolar e das salas de aula. Conteúdos de livro textos e métodos de ensino tem sido cautelosamente selecionados de modo a certificarem-se que somente temas socialmente depurados sejam discutidos. Como resultado, ELT não tem correspondido de forma completa às demandas da Pedagogia Crítica, sendo o ensino de línguas ainda visto, principalmente, como uma atividade cognitiva com poucas implicações sociopolíticas. Mesmo quando as dimensões sociais da linguagem são reconhecidas, a realidade social do ensino e aprendizagem de línguas é representada por uma perspectiva rasa, em que o contexto social é tratado apenas como quem está falando para quem sobre o que (AKBARI, 2008, p. 278). ${ }^{13}$

13The conservative forces that control education and society at large have tried to keep critical ideas out of school curricula and classrooms. Coursebook contents and teaching methods have been cautiously selected to make sure that only socially refined topics are addressed. As a result, ELT has not been 
Tomemos como exemplo de nossa análise as sequências At the mall - shopping (APÊNDICE A) e Asking for a doctor (APÊNDICE B). Compreendemos que ambas apresentam características que podem representar o material didático como um todo.

A sequência At the mall - shopping apresenta um casal aparentemente hetero, branco, fazendo compras em um shopping com seu filho, que parece ser biológico. No início do diálogo, percebemos que a intenção do casal era comprar roupas para ele. $\mathrm{O}$ garoto, já no interior da loja, demonstrando pouco interesse, experimenta duas peças de roupa e as refuta. A mãe então decide comprar roupas para si mesma. Enquanto ela experimenta um grande número de itens, pai e filho aparecem sentados e entediados, aguardando-a. Ao final do diálogo, eis que surge a mãe com suas compras, talvez saindo da loja. Ao vê-la com um grande número de sacolas, o pai dirige-se ao filho dizendo-lhe que aquele seria seu futuro. Nesse momento, o texto levanos a compreender que ele está se referindo ao ato consumista da mulher, talvez especialmente no que se refere ao consumo de roupas. A conclusão do diálogo é uma fala uníssona entre pai e filho, a partir da qual eles expressam sua visão de que ser consumista ou comprar roupas em grandes quantidades é uma característica intrínseca das mulheres, caracterizando-as como tal.

Elaborado dessa forma, o diálogo parece-nos reforçar estereótipos e assumir um currículo oculto que contribui para corroborar valores que sustentam um status quo que, como mencionamos, pode inserir os aprendizes e os docentes, como membros da sociedade, em condições que os oprimem. Compreendemos que o texto, de fato, reforça uma visão estereotipada tanto da ideia de mulher quanto de homem. Ele o faz quando estabelece que o consumismo define as mulheres como tal e que o desinteresse pela moda, pela autoimagem ou pelo consumo de roupas define, por sua vez, os homens como homens. De modo bastante sutil, o diálogo apresenta como

completely responsive to the demands made by a CP, and still language teaching is viewed mainly as a cognitive activity with few socio-political implications. Even when the social dimensions of language are acknowledged, the social reality of language learning and teaching is represented from a narrow perspective where social context is only treated as who is talking to whom about what (AKBARI, 2008, p. 278). 
natural o consumismo, especialmente em shoppings, pois em momento algum o questiona. Da mesma forma, consideramos que ele se alinha com uma perspectiva heteronormativa, assumindo essa condição como neutra e natural, uma vez que em momento algum do diálogo ou do material didático como um todo questiona essa norma, seja ao escolher para os diálogos apenas casais representativos de relações hétero, seja ao omitir ou não incentivar qualquer debate sobre o assunto, como, por exemplo, sobre as múltiplas possibilidades de configuração familiar.

A sequência Asking for a doctor, por sua vez, apresenta um diálogo que ocorre em um hotel. Nele, uma hóspede, aparentemente jovem, liga para a recepção e pergunta se seria possível ver um médico. A recepcionista prontamente responde dizendo que enviará o médico do hotel para vê-la em seu quarto. O profissional assim o faz e, após examiná-la, preenche a receita. Entregando-lhe, diz que os medicamentos podem ser aviados pelo hotel caso ela o deseje. Hóspede, recepcionista e médico aparentam ser brancos.

Tal qual apresentado, o diálogo parece evidenciar um currículo oculto ao veicular a ideia errônea de que o acesso a serviços de saúde é algo corriqueiro e comum a todos. Ele o faz quando não antagoniza a situação mostrada no diálogo, ou seja, uma pessoa sendo atendida imediatamente por um médico em um hotel, à situação do acesso à saúde no Brasil, ou, em especial, no Estado de São Paulo, seja no próprio diálogo, seja nas atividades a ele relacionadas. Em outras palavras, quando não questiona se os próprios alunos ou alunas têm esse tipo de acesso e, se não têm, por qual motivo.

Compreendemos que uma dimensão crítica poderia ser contemplada ao se trazerem a tona questões como: preços e custos das roupas versus poder aquisitivo dos brasileiros, incluindo, especialmente, o dos alunos e o de suas famílias; consumismo versus necessidade real; trabalho escravo versus produção em larga escala e necessidade de emprego; consumo versus organização financeira pessoal; diversas possibilidades de configuração familiar; estereótipos sobre gêneros e sexualidade - associadas à temática proposta pelo diálogo At the mall - shopping - e acesso à saúde versus condição financeira; direito ao acesso público à saúde versus condições precárias do sistema de saúde brasileiro - associadas à temática trazida pela sequência Asking for a doctor. De fato, essas questões podem balizar a escolha de códigos que poderão trazer à tona problemas enfrentados 
pelos alunos ou com os quais se identificam em sua vida quotidiana. Vale lembrar que tais problemas poderão ser identificados pelo diálogo entre professores e alunos, seja com o intuito de repensar o design do material didático, seja com a intenção de elaborar atividades complementares para a sala de aula, ao utilizá-lo como está.

\section{Conclusões}

Buscamos, neste artigo, apresentar nossa análise do material didático de inglês do Centro de Estudos de Línguas do Estado de São Paulo no que se refere à presença ou à ausência de uma dimensão crítica em seu design.

De forma geral, compreendemos que o material didático parece não se comprometer com uma perspectiva crítica, optando por uma concepção de língua como exercício intelectual, desconectado de questões político-sociais, assumindo um currículo oculto que sugere uma falsa neutralidade, quando, de fato, como dissemos, esconde ideologias que o comprometem com o não questionamento do status quo, o qual, muitas vezes, submete alunos e professores à condição de opressão.

De fato, concordando com Akbari (2008), percebemos que, apesar de considerar as dimensões sociais da linguagem (quem fala o que e para quem), ele parece ignorar o contexto social e político inerente ao âmbito do ensino e aprendizagem e à vida dos indivíduos que dele fazem parte. Referimo-nos, neste caso, aos aprendizes do CEL - seu público-alvo - e aos respectivos contextos em que se inserem.

Consideramos, dessa forma, que o design do material didático parece não contribuir plenamente para o estabelecimento de uma educação cidadã, conforme anunciado como um de seus objetivos em seu texto de apresentação. Com efeito, concordamos com Riasati e Mollaei (2012) quando elegem a perspectiva da Pedagogia Crítica como estrada para uma proposta de tal natureza, ou seja, visando à preparação para a cidadania em uma sociedade democrática.

Compreendemos, enfim, que nossas análises poderão balizar a produção de material didático em que se considere a dimensão crítica em seu design tanto para o inglês como para os outros idiomas ofertados pelos Cestos de Estudos de Línguas do Estado de São Paulo. 


\section{Referências}

AKBARI, R. Transforming lives: introducing critical pedagogy into ELT classrooms. ELT Journal, v. 63, n. 3, p. 276-282, 2008.

AUERBACH, E. R. The politics of the ESL classroom: issues of power in pedagogical choices. In: TOLLEFSON, James. W. (Org.). Power and inequality in language education. Cambridge: Cambridge University Press, 1995. p. 9-33.

BENESCH, Sarah. Critical English for academic purposes: theory, politics, and practice. New Jersey: Taylor \& Francis, 2001.

CEL TEACHERS. About us [Blog Internet]. Blogspot, 2009. Disponível em: <https://celteachers.blogspot.com.br/>. Acesso em: 10 jan.2018.

CANAGARAJAH, S. Critical pedagogy in L2 learning and teaching. IN: HINKEL, Eli. (Org.). Handbook of research in second language teaching and learning. New Jersey: Routledge, 2005. p. 931-949.

CAMPOS, A. R. et al. Inglês: livro do estudante. São Paulo: Secretaria de Educação do Estado de São Paulo, 2014. (apostila de inglês)

CROOKES, G. V. Critical ELT in action: foundations, promises, praxis. New York: Routledge, 2013.

FREIRE, P. Pedagogia do oprimido. 50. ed. São Paulo: Paz e Terra, 2011.

. Pedagogy of the opressed. New York: Seabury Press, 1970.

GIROUX, H. A. Teachers as intellectuals: toward a critical pedagogy of learning. South Hadley, Massachusetts: Bergin \& Garvey, 1988.

- Radical pedagogy as cultural politics: beyond the discourse of critique and anti-utopianism In: MCLAREN, P. Critical pedagogy and 
Dimensão crítica e design de material didático...

predatory culture: oppositional politics in a postmodern era. New York: Routledge, 1995. p. 29-57.

GIROUX, H. A. et al. (Ed.). Curriculum and instruction. Berkeley, CA: McCutchan, 1981.

GUILHERME, M. Critical citizens for an intercultural world: foreign language education as cultural politics. Clevedon, UK: Multilingual Matters LTD, 2002.

KUMARAVADIVELU, B. The postmethod condition: (e)merging strategies for second/foreign language teaching. TESOL Quarterly, v. 28, n 1, p. 27-48, 1994.

. Toward a postmethod pedagogy. TESOL Quarterly, v. 35, n. 4, p. 537-560, 2001.

Beyond methods: macrostrategies for language teaching. New Haven: Yale University Press, 2003.

- Understanding language teaching: from method to postmethod. New Jersey: Lawrence Erlbaum Associates, 2006.

MCLAREN, P. Critical pedagogy and predatory culture. London: Routledge, 1995.

- Life in schools: an introduction to critical pedagogy in the foundations of education. New York: Longman, 1989.

PENNYCOOK, A. The concept of method, interested knowledge, and the politics of language teaching. TESOL Quarterly, v. 23, n. 4, p. 589$618,1989$.

Introduction: critical approaches to TESOL. TESOL Quarterly, v. 33, n. 3, p. 329348, 1999.

PENNYCOOK, A. Critical applied linguistics: an introduction. Mahwah, New Jersey/London: Lawrence Erlbaum Associates, Publishers, 2001.

RAJAGOPALAN, K. Por uma linguística crítica: linguagem, identidade e a questão ética. São Paulo: Parábola Editorial, 2003. 
RIASATI, M. J.; MOLLAEI, F. Critical pedagogy and language learning. International Journal of Humanities and Social Science, v. 2, n. 21, 2012.

SANTOS, K. C. Construção multicultural: reflexões sobre políticas alternativas para o ensino de língua estrangeira. 2002. Tese (Doutorado em Língua Inglesa e Literaturas Inglesa e Norte-Americana) Faculdade de Filosofia, Letras e Ciências Humanas, Universidade de São Paulo, São Paulo, 2002.

SHOR, I. Empowering education: critical teaching for social change. Chicago: University of Chicago Press, 1992.

SIQUEIRA, S. English as a lingua franca: for a critical intercultural pedagogy. In: LAPRIORE, L.; GRAZZI, E. (Org.). Intercultural communication: new perspectives from ELF. Roma: Roma Tre Press, 2016. p. 189-209.

. English for the real world: sharing ideas and possibilities of Critical Pedagogy oriented materials. Jornada Internacional de Línguística Aplicada Crítica (JILAC). Minicurso. Brasília, 2017

SIMON, R. I. For a pedagogy of possibility. In: SMYTH, J. (Org.). The critical pedagogy networker. Victoria, Australia: Deakin University Press, 1988. p. 1-4.

SLATTERY, P. Curriculum development in the postmodern era. 2. ed. New York: Routledge, 2006.

SOUZA, R. F. Implicações do uso de material didático virtual livre em contexto formal de ensino-aprendizagem de italiano como LE/L2: a perspectiva dos problemas de ensino. Tese (Doutorado em Língua e Literatura Italiana) - Faculdade de Filosofia, Letras e Ciências Humanas, Universidade de São Paulo, São Paulo, 2014.

WALLERSTEIN, N. Language and culture in conflict: problem-posing in the ESL classroom. Nova York: Addison-Wesley Publishing Company, 1983. 
Dimensão crítica e design de material didático...

WIDDOWSON, H. G. Aspects of language teaching. Oxford: Oxford University Press, 1990.

\section{APÊNDICE 1 - Apostila de inglês do CEL - Volume 3 - At the} mall - shopping (CEL, p. 11)

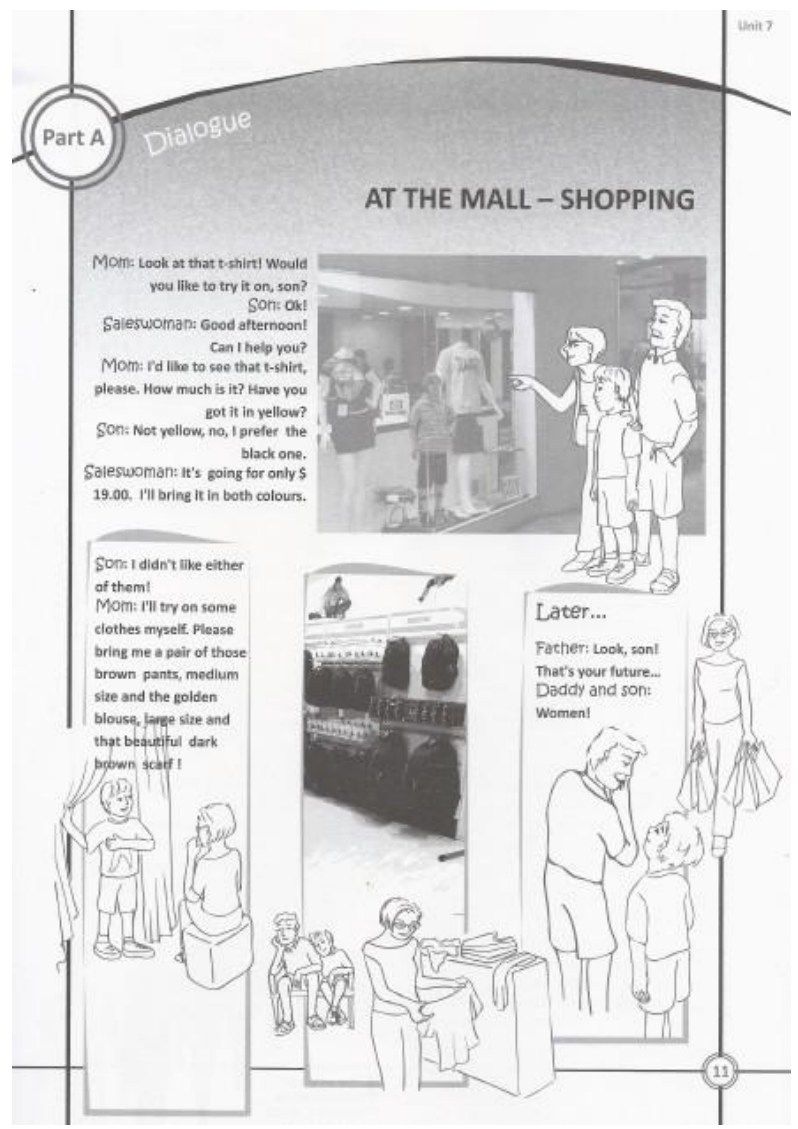

APÊNDICE B - Apostila de inglês do CEL - Volume 2 - Asking for a doctor (CEL, p. 51 


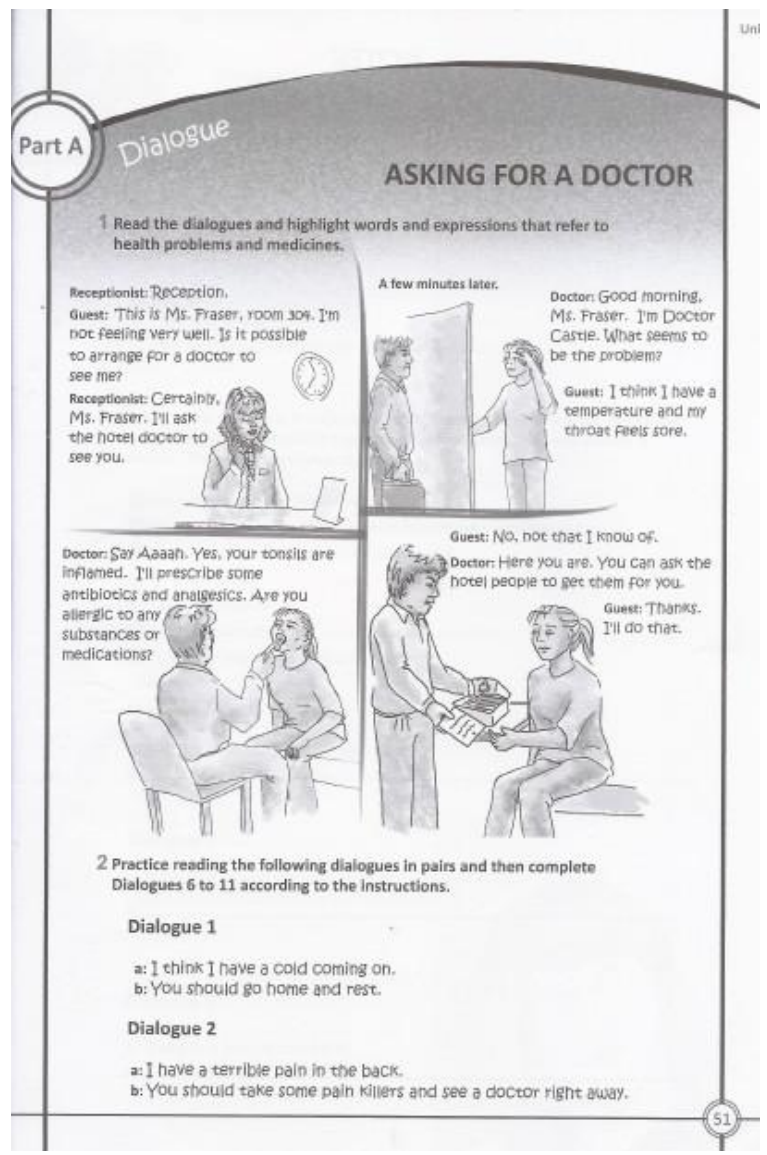

Recebido em: 01/08/2018 Aceito em: 30/11/2018

Title: Critical perspective and material design in the context of the Center for Language Studies of the State of São Paulo: the case of English 